\title{
AOR
}

Selected Papers of \#AolR2018:

The $19^{\text {th }}$ Annual Conference of the

Association of Internet Researchers

Montréal, Canada / 10-13 October 2018

\section{WHEN, WHERE, AND HOW IS DIGITAL SOUND?}

Jeremy Wade Morris, in discussing podcast archiving, notes that internet archives like the Wayback Machine have had much more focus on preserving visual and text content than sound. Internet Research has similarly traditionally had less engagement with sound than with other forms of digital content. This panel seeks to contribute to ongoing work to bring Sound Studies and Internet Studies into better conversation with each other, taking digital sound as a common object and examining it in different cases and through different methods to provide a richer understanding of the role sound plays in shaping our online experiences.

The papers coalesce around their common object of inquiry, digital sound, providing depth of understanding about the subject matter by approaching from different directions. Moreover, the papers help to illuminate each other by taking different approaches to common themes. Morris and Stanfill raise key questions about who tends to be included and excluded in circuits of production as well as whose digital sound tends to be seen as valuable. Papers by Morris, Stanfill, and Sterne and Razlogova all ask about how, despite rhetorics of democratization and variety, forms of digital sound may be becoming standardized through technological and social means. The Morris and Murray papers call attention to the ways the specific affordances of particular digital production technologies shape (though do not determine) the kinds of production that become prevalent in a given moment. There are also methodological convergences: papers by Sterne and Razgolova and Murray both take as their object of inquiry technology makers, and papers by Stanfill and Murray both use press coverage as the site of investigation. Finally, the papers by Stanfill and Murray ask questions about what people believe is socially proper or correct in the case of digital sound.

In these ways, this panel represents both an important contribution to our understanding of contemporary issues in digital sound as well as relating to broader questions central to internet research. 


\section{PODCASTRE: ARCHIVING THE PROMISES OF A DISRUPTIVE FORMAT}

Jeremy Wade Morris

University of Wisconsin-Madison

As the popular press and industry insiders have noted (Blattberg, 2014; Roose, 2014; Sillesen 2014), we are in the midst of a "Golden Age of Podcasts": a cultural moment where the choice for ambitiously and artfully produced digital audio abounds, and where new voices and listeners connect daily through earbuds, car stereos, home speakers, and office computers. There are now over 300,000 podcast feeds and close to 8 million individual episodes in over 100 languages. There's a podcast on almost every subject imaginable, from popular shows like S-Town and Radiolab to lighter fare like the wrestling podcast Wrestlespective or shows that cover social issues like sexuality, identity, race or politics, (e.g. Strange Fruit, This Week in Blackness, etc.). In 2016, an estimated 57 million Americans listened to podcasts every month (Edison, 2016). Apple, the leading distributor of podcasts, counted 10 billion streams and downloads in 2016 alone (Washenko, 2016).

This is not, however, podcasting's first "Golden Age". The format's longer history includes several moments where there were hopes and promises this online format might upend traditional forms of media production and distribution. When podcasting emerged in the early 2000s, and as it grew over the decade, the format was consistently heralded for giving listeners greater control to time-shift and place-shift audio, while relatively inexpensive digital media tools opened up the power of broadcasting to a much wider segment of producers and users and expanded the diversity and quantity of available audio content online (Berry 2006, Crofts et. al 2005, Newitz 2005, Terdiman 2004).

Yet despite the recent explosion of interest in podcasts, two decades' worth of repeated reports of podcasting's value, and growing academic attention to the study of sound (e.g. Sound Studies), the sounds of this online format's past and present remain mystifyingly difficult to analyze. Qualitative audio analysis often has to be done in realtime (or longer) and quantitative analysis is usually done only after the audio has been transcribed to text. The sounds of podcasting's booming audio culture thus remain relatively closed off as a research resource, far less usable than text as a source of information or insight. Podcasts are also shockingly vulnerable, despite how ubiquitous, free and available they appear; podcast feeds end abruptly, cease to be maintained, or become housed in proprietary databases, like iTunes, which are difficult to search with any rigor. As the industry grows in popularity, professionalization and commercialization also threaten to streamline production and limit podcasting's democratic diversity and accessibility. We know from studying the histories of film, television, and radio that the early productions of any medium are invaluable texts but that they are also the ones with the greatest risk of being lost. We know this is doubly true for web-based digital objects, which bring new challenges for saving, locating and retrieving data over time (Brügger, 2010). 


\section{Saving New Sounds}

This paper documents one effort to save these new sounds: a database I have been building called PodcastRE (short for Podcast Research). Currently the site (http://podcastre.org) tracks over 1300 podcast feeds, and indexes and stores over 250,000 audio files, along with all the associated metadata from the RSS feeds. The web interface allows users to search the database via keyword (e.g. title, author, description elements, etc.). There are also several thousand interactive transcripts which allow users to find specific keywords within individual episodes (e.g. Election, ISIS, Hamilton, etc.) and narrow their search results accordingly.

While the database provides a departure point from which to launch a more thorough investigation of the history of the format, it also raises a number of significant challenges regarding saving and researching digital audio. There's the incredible inconsistency of podcast metadata, which comes via both RSS feeds and the ID3 tags within the audio files themselves, both of which depend on which platform hosts the podcast and which program was used to created it. There's also the instability of the object itself...podcasts are no longer static audio files like they were in podcasting's early years. Technologies like dynamic advertising and dynamic insertion mean that the audio file itself can change periodically over time. Beyond these technical questions, there are the more serious cultural questions the database raises about what to save (which voices, which sounds) and how to go about doing so; it's easy to automate scraping the most popular podcasts but sourcing the more marginalized more independent shows is a much more manual affair.

In this paper, I will use the database as a starting point for a discussion about the challenges digital and web audio presents for preservation, though I also want to reflect on what podcasts tell us about the Web's rich sonic past and present; an aspect of its history that is often overlooked in more visually-focused attempts to archive the web (e.g. the Wayback Machine).

\section{Preserving Promises}

It remains an open question whether or not podcasting's early hopes and promises have been realized. Podcast listening, for example, still skews male, and towards younger, whiter, and more urban and affluent audiences. Similarly, podcast production struggles to live up to the highly democratized form of audio production it was meant to be; the most critically acclaimed and top-rated podcasts are often similar in style and tone, showcasing a culturally homogenous representation of the field. Given the optimism and hope surrounding podcasting as a platform for giving voice to a wide number of perspectives, there is a critical need to facilitate more rigorous quantitative and qualitative work on the medium, both as a new format and as a potentially transformative cultural practice. Rather than dismissing podcasting as simply another over-hyped web 2.0 technology, this paper and the project it describes takes seriously the claim that podcasting could represent the realization of an alternate cultural model of broadcasting (Sterne et. al. 2008). 
Considering the countless lost recordings of early radio shows or silent films, PodcastRE aims to avoid the same fate for podcasts, whether professionally-produced shows or the hundreds of thousands of amateur podcasts that are being produced in our communities. By providing a platform for sophisticated and rigorous analysis of this emerging yet vulnerable media format, I hope to show that what today's podcasters are producing will have value in the future, not just for its content, but for what it tells us about audio's longer history, about who has the right to communicate and by what means (Sterne et. al. 2008). We may be in a "Golden Age" of podcasts but if we're not making efforts to preserve and analyze these resources now, we'll likely find ourselves in the same sonic conundrum many radio, film or television historians now find themselves: writing, researching and thinking about a past they can't fully see or hear.

\section{References}

Berry, R. (2006). Will the iPod kill the radio star? Profiling podcasting as radio. Convergence: The International Journal of Research into New Media Technologies, 12, 143-162.

Blattberg, E. (2014, November 19). The podcast enters a new golden age. Digiday. Retrieved from http:// digiday.com/publishers/nielsenes-rise-podcast/

Brügger, Neils (ed.). 2010. Web History. New York: Peter Lang

Crofts, S., Dilley, J., Fox, M., Restsema, A., \& Williams, B. (2005). Podcasting: A new technology in search of a business model. First Monday, 10, 1-20.

Edison Research (2016). The Podcast Consumer 2016. Retrieved from http://edisonresearch.com/the-podcast-consumer-2016.

Newitz, Analee. 2005. "Adam Curry Wants to Make You an iPod Radio Star." Wired, March, 111-113.

Roose, K. (2014, October 30). What's behind the great podcast renaissance? New York Magazine.

Sillesen, L. B. (2014, November 24). Is this the golden age of podcasts? Columbia Journalism Review Retrieved from http://www.cjr.org/behind_the_news/is_this_the_golden_age_of_ podc_1.php?pageDall\# sthash.BZ13l2b8.dpuf

Sterne, J., Morris, J. W., Baker, M., \& Moscote Freire, A. (2008). The politics of podcasting. Fibreculture, 13.

Washenko, Anna. (2016, 9 December) Apple Saw 10 billion Podcast Downloads and Streams in 2016. Radio and Internet News. Retrieved from: http://rainnews.com/applesaw-10-billion-podcast-downloads-and-streams-in-2016/ 


\title{
SAMPLE, REMIX, AND MASHUP FOR ME, BUT NOT FOR THEE: DIGITAL MUSIC PRODUCTION AT THE INTERSECTION OF RACE AND THE LAW
}

\author{
Mel Stanfill \\ University of Central Florida
}

There has much enthusiasm about the potential for participatory digital culture to reshape who can speak and be heard (Jenkins 2006; Lessig 2008). However, only sometimes do people think of forms of transformative digital creativity as legitimate or socially appropriate. I argue that in the case of digital music production, who does what to whom - whether sample, remix, or mashup-matters quite a lot. Particularly, I step into the space between Yew and Monroy-Hernández's (2014) argument that remixers serendipitously find content to appropriate and Brøvig-Hanssen's (2017) description of how mashup can contest social inequality to argue that excitement over participatory culture has been insufficiently attentive to the role of historical and ongoing structures of inequality such as the history of white appropriation of Black music. Through an analysis of popular press conversations, this paper interrogates which instances of digital music production in remix, mashup, and sampling, building on whose work, by whom, are considered socially legitimate or creative, and which are considered theft. Through this analysis, I answer the broader question of who gets to be an "artist" being "copied" and who's just raw material.

\section{Previous work}

The current research builds on three bodies of literature. The first considers how law enables or constrains technology. Scholars have argued that sometimes law overrides technology, legally preventing uses that are technologically possible (Boyle 2008; Gillespie 2007; Petersen 2015), and other times technology is used instead of law to control behavior (Gillespie 2007; Lessig 1999), or even to exceed the letter of the law (Favale 2014; Gillespie 2007; Tushnet 2014), making legally permissible actions technologically impossible. This work shows that the relationship of law and technology is not simple but rather must be interrogated.

The second body of work underpinning this paper considers how contemporary beliefs struggle to account for diverse forms of remix creativity. On one hand, these are beliefs built into law: "Legal conceptions of musical creativity derive from practices within Western classical music traditions that had become increasingly dominant by the end of the nineteenth century" (Arewa 2013, 70), protecting music that can be notated on a score and systematically disregarding other forms. On the other hand, these are popular beliefs, as shown by the interviews with everyday people in Aram Sinnreich's (2010) work on configurable culture.

A third area of research interrogates how marginalized groups find their creativity socially and legally devalued. As Barron notes, "musical genres associated primarily with African-American musicians-especially rap, jazz and the blues-have been especially difficult to reconcile with legal thinking organized around the category of the 
musical work" (Barron 2006, 33), because the way law thinks about music "limits its capacity to accommodate non-Western and non-classical music as music" (Barron $2006,31)$. Culturally, as Sinnreich $(2010,206)$ notes, "mash-ups tend to follow a more traditional European structural logic, while hip-hop and turntablism tend to follow a more traditional Afro-diasporic structural logic. In a word, mash-ups are coded as 'white,' while hip-hop is coded as 'black," and this has important bearing on their social legitimacy. This tendency is also, from the other direction, why African-American and indigenous traditions have seemed free for white and Western artists to pillage.

\section{Methods}

Drawn from a larger project that computationally analyzes trends in the news coverage of digital music production in remix $(48,217$ stories), mashup $(23,163)$, and sampling $(152,517)$ from $2009-2014$, this project focuses on the random sample of .1\% of the stories that was human-coded and used to train the model. Using discourse analysis, I examine when and how these forms of digital music production are socially considered creative, original, copying, and/or legal.

\section{Findings}

Preliminary analysis suggests several themes in the popular conversation around digital musical production like remix, mashup, and cover songs. First, the stereotype of Black criminality endures-Biz Markie was famously told 'Thou shalt not steal' by a judge over sampling in 1991, and such arguments are still with us. Second, there is a trope of white genius, similar to Hesmondhalgh's (2006) criticism of how Moby's sampling of blues recordings was treated as his creativity alone. Third, colonial "discovery" of things other people knew about before persists as white artists bring indigenous and African diaspora music into the white mainstream. Fourth, the ideology of the isolated author who creates from nothing - a trope that artificially identifies some culture as raw material rather than artistry-is still very strong despite widespread belief in a democratizing era of remix creativity.

\section{Conclusion}

Ultimately, I argue, popular conversations about digital music production show that inspiration, reuse, or remix from someone else's work can legitimately be done only to those figured as raw material and only by those figured as capital-A Artists. When Black artists sample someone else's work, it's "theft." When white folks like the Rolling Stones or Eric Clapton copy blues sounds or Moby samples blues recordings, it's "homage." Arewa $(2013,80)$ notes that "borrowings from blues highlight in some ways in which acts of appropriation, which are endemic and essential elements of culture, may have fundamentally different meanings depending on context." This paper traces out that interrelationship between meaning and context using the digital music production cases of remix, mashup, and cover song. 


\section{References}

Arewa, Olufunmilayo B. 2013. "Making Music: Copyright Law and Creative Processes." In A Companion to Media Authorship, edited by Jonathan Gray and Derek Johnson, 6987. New York, NY: John Wiley \& Sons.

Barron, Anne. 2006. "Introduction: Harmony or Dissonance? Copyright Concepts and Musical Practice." Social \& Legal Studies 15 (1): 25-51.

https://doi.org/10.1177/0964663906060972.

Boyle, James. 2008. The Public Domain: Enclosing the Commons of the Mind. New Haven, CT: Yale University Press.

Brøvig-Hanssen, Ragnhild. 2017. "Musical Recycling: Mashup Aesthetics and Authorship." AolR Selected Papers of Internet Research 6. https://spir.aoir.org/index.php/spir/article/view/1289.

Favale, Marcella. 2014. "Death and Resurrection of Copyright between Law and Technology." Information \& Communications Technology Law 23 (2): 117-35. https://doi.org/10.1080/13600834.2014.925631.

Gillespie, Tarleton. 2007. Wired Shut: Copyright and the Shape of Digital Culture. Cambridge: Massachusetts Institute of Technology Press.

Hesmondhalgh, David. 2006. "Digital Sampling and Cultural Inequality." Social \& Legal Studies 15 (1): 53-75. https://doi.org/10.1177/0964663906060973.

Jenkins, Henry. 2006. Convergence Culture: Where Old and New Media Collide. New York, NY: New York University Press.

Lessig, Lawrence. 1999. Code: And Other Laws of Cyberspace. New York, N.Y.: Basic Books.

York: Penguin.

Petersen, Jennifer. 2015. "Is Code Speech? Law and the Expressivity of Machine Language." New Media \& Society 17 (3): 415-31.

https://doi.org/10.1177/1461444813504276.

Sinnreich, Aram. 2010. Mashed Up: Music, Technology, and the Rise of Configurable Culture. Amherst: University of Massachusetts Press.

Tushnet, Rebecca. 2014. "All of This Has Happened Before and All of This Will Happen Again: Innovation in Copyright Licensing." Berkeley Technology Law Journal 29 (3): 1447-88.

Yew, Jude, and Andrés Monroy-Hernández. 2014. "Harnessing Serendipity: A Study of Accidental Creative Collaboraotins in Two Online Remixing Communities." AolR 
Selected Papers of Internet Research 4.

https://spir.aoir.org/index.php/spir/article/view/1002.

\title{
ARTIFICIAL INTELLIGENCE AND THE POLITICS OF MEDIA AESTHETICS: THE CASE OF ONLINE MUSIC MASTERING
}

\author{
Jonathan Sterne \\ McGill University \\ Elena Razlogova \\ Concordia University
}

This paper offers an extended case study of LandR, a Montreal company that uses machine learning (branded as "Artificial Intelligence") to automate music mastering and create a platform strategy around it. We argue that 1) LandR extends some of the standardizations of sound media aesthetics first developed for music recommendation and recognition engines; 2) LandR's success is defined in part by limiting the problems it is trying to solve while finding ways to market new uses for its products, thus offering a new chapter in the history of mastering, a set of audio techniques that has evolved alongside the history of audio formats; 3 ) LandR therefore offers an early test case for Al's effects on other media industries, showing that industries that are highly concentrated and whose work is mystified for everyday users are especially susceptible to automation; and, finally, 4) LandR also offers an early test case for arguments about $\mathrm{Al}$ and labour, showing its effects on the labor force can be uneven and contradictory, shaped by the specific contours and limits of the industry rather than the "impact" of Al itself.

\section{Scholarly Context}

Recent critical scholarship on artificial intelligence has focused on four main areas: labor and automation, bias and inclusion, rights and liberties, and ethics and governance (Campolo et al, 2017). Yet commercial applications of Al (which really rebrand a specific type of $\mathrm{Al}$, machine learning) has been notably successful in a fifth area: media aesthetics. As wide range of scholars have argued, the standardization of media aesthetics over the long twentieth century has shaped the look, sound, and feel of mediated experience for most users (Sterne, 2012; Bratton, 2016; Murray, 2018). Standardization cuts both ways: it provides clear protocols for interoperability and circulation while also creating barriers to entry, opportunities for market concentration, and limits on artistic expression (Bowker and Starr, 1999; Mulvin forthcoming). In sound media aesthetics specifically, practical, tacit knowledge has remained valuable as recording technologies and audio formats evolved, and may yet persist in the machine learning and black-boxed algorithm era (Horning). Our study aims to bring problems of media aesthetics into the critical conversation about Al, and problems introduced by $\mathrm{Al}$ into the critical conversation about media aesthetics, while also contributing to ongoing discussion in both these fields. Additionally, our project contributes to the burgeoning intersection of sound studies, popular music studies, and new media studies by 
considering how these fields are bound up "transsectorially," where innovations in one field of technology or practice wind up shaping and conditioning another (Théberge 1997, Born 2013, Brøvig-Hassen and Danielsen, 2016).

\section{Methods}

For this paper, we used a range of methods drawn from the cultural study of technology (Slack and Wise, 2014) and Science and Technology Studies (Gillespie, Boczkowski and Foot, 2014). As participant observers, we visited LandR headquarters, participated in music mastering sessions, and spent time with musicians and mastering engineers who were connected with LandR in one way or another (Novak, 2013). We conducted long-form interviews with the co-founder of LandR, Justin Evans, as well as a number of professional mastering engineers and musicians (Pinch and Trocco 2002). We also spent time in online forums, following discussions among musicians and engineers regarding LandR (Massenari 2015). We constructed a critical history of mastering technologies and techniques (Sterne 2012). One of us spent many hours actually working with the sound engine and the interface, as well as subjecting the same material to "non-Al" mastering by working mastering engineers (Chapman and Sawchuk, 2012). Finally, we also analyzed LandR as a self-described "platform" for mastering, considering its operational protocols, interface, and self-presentation online-treating each of these elements as rhetorical and political, rather than merely functional (Gillespie 2010, Chun 2011).

\section{Bibliography}

Born, G. (2013). Introduction -- Music Sound and Space: Transformations of Public and Private Experience. In G. Born (Ed.), Music, Sound and Space: Transformations of Public and Private Experience (pp. 1-70). Cambridge: Cambridge University Press.

Bowker, G. C., \& Star, S. L. (1999). Sorting Things Out: Classification and Its Consequences. Cambridge: MIT Press.

Bratton, B. (2016). The Stack: On Software and Sovereignty. Cambridge: MIT Press.

Brøvig-Hanssen, R., \& Danielsen, A. (2016). Digital Signatures: The Impact of Digitization on Popular Music Sound. Cambridge: MIT Press.

Campolo, A., Sanfilippo, M., Whittaker, M., \& Crawford, K. (2017). Al Now 2017 Report. Retrieved from https://ainowinstitute.org/AI_Now_2017_Report.pdf

Chapman, O. B., \& Sawchuk, K. (2012). Research-Creation: Intervention, Analysis and "Family Resemblances." Canadian Journal of Communication, 37(1). https://doi.org/10.22230/cjc.2012v37n1a2489

Chun, W. H. K. (2011). Programmed Visions: Software and Memory. Cambridge: MIT Press. 
Gillespie, T.,, Boczkowski, P., \& Foot, K.A. (2014). Media Technologies: Essays on Communication, Materiality and Society. Cambridge: MIT Press, 2014.

Gillespie, T. (2010). The Politics of "Platforms." New Media and Society, 12(3), 347364.

Horning, S. (2015). Chasing Sound: Technology, Culture, and the Art of Studio Recording from Edison to the LP. Baltimore, MD: Johns Hopkins University Press.

Massanari, A. L. (2015). Participatory Culture, Community, and Play: Learning from Reddit.

Mulvin, D. (Forthcoming). Proxies: The Cultural Work of Standing In. Cambridge: MIT Press.

Murray, S. (2018). Bright Signals: A History of Color Television. Durham: Duke University Press.

Novak, D. (2013). Japanoise: Music at the Edge of Circulation. Durham: Duke University Press.

Pinch, T., \& Trocco, F. (2002). Analog Days: The Invention and Impact of the Moog Synthesizer. Cambridge: Harvard University Press.

Slack, J. D., \& Wise, J. M. (2014). Culture and Technology: A Primer, Second Edition. New York: Peter Lang.

Sterne, J. (2012). MP3: The Meaning of a Format. Durham: Duke University Press.

Théberge, P. (1997). Any Sound You Can Imagine: Making Music/Consuming Technology. Hanover: Wesleyan University Press.

\section{USABLE SOUNDSCAPES: UI SOUNDS, MOBILE MEDIA, AND THE DELICATE NATURE OF ATTENTION}

Sarah Murray

University of Michigan

\section{Noisy but Useful? UI Sounds in Mobile Media}

If hearing is the perception of sound, but listening is the conscious choice to attend to it, then the goal of a user experience (UX) sound product designer is to build a soundtrack of digital life that inverts this relationship. While we tend to place social judgment on those who hear but don't listen, digital sound is often a carefully constructed inverse: meant to be listened to, but not heard. Or, as Will Littlejohn, sound design director at Facebook explains, "We are not in the service of being noticed" (Introcaso, 2017). This paper considers how designers and users of UI sounds on mobile media platforms 
negotiate the space between necessity and noise, and how that negotiation takes shape in different cultural contexts and geographies.

To avoid notice in digital flows of attention is a particular design challenge. Sound interfaces composed for mobile platforms are built to curate responsiveness, but must also negotiate the thin line between being helpful and being annoying. User interface (UI) sounds must quite literally strike the right chord - or beep - that captures and redirects attention without disrupting its flow for the connected user. As Littlejohn notes, sound in the "real world" of the mobile everyday is vastly different than the sounds of contained narrative worlds like film and television. Beeps, rings, and vibrating hums must accommodate our movement through routinized life; these sounds must be usable enough to make their presence justifiable, but not so present that users choose to tune out. At the same time, sound affords a modicum of control for the connected, mobile body in exchange for a certain type of datafied feedback - to notify, to remind, to mute, or to demarcate the lines between public and private is also an agreement to be tracked, registered, and tuned in to particular modes of measurement and quantified participation.

Part of a larger project on "necessary noise" and digital selfhood (e.g., silencing social media, designing affective alarm systems, curating notifications) this paper focuses exclusively on the UI sounds of mobile media devices and platforms. I suggest that soundtracks and "sound families" of beeps and tones emerge from material design decisions and user strategies that negotiate a number of tensions - that between being attended to and being annoyed, between the care structures of good design and the imperatives of attention economies, and between the intimate universality of branded sounds (e.g., Apple's ringtone) and the personal soundscapes created by users. The sounds that emerge are a result of the affective, economic, and material negotiations of market-driven attention on digital platforms, the place of sound in the mundane movements of the everyday, and the subjective nature of taste cultures and personal histories.

\section{Beyond Sound "Effects"}

While there is substantial work on sound design in narrative and entertainment media (Collins, 2008; Weis and Belton, 1985; LoBrutto, 1994) and recent survey work on the uses and effects of sound in mobile media applications (Lu, et al, 2009), this project contributes to current scholarship on the critical understanding of sound as a built and negotiated landscape of everyday media practice (Sterne, 2012; Bull, 2001, 2014). I bring together literature on the attention economy (Fairchild, 2007; Hearn, 2010; Crogan and Kinsley, 2012; Bucher, 2012) and usability theory in design studies (Norman, 2004; Garrett, 2010; Ankerson, 2018), two areas where sound in the digital context has not been thoroughly considered and that come to necessary light when we take sound seriously as a site of designed media interaction.

This paper addresses questions such as: How and when does digital sound become noise? How is this connected to the imperatives of attention economies of clicks, likes, impressions, and other measurable modes of participation and non-participation? How is a highly subjective experience like the affective response to sound anticipated, 
managed, and cared for in the design of UI sounds and in the negotiated use of them as affordances? Ultimately, I argue that sound in the mobile everyday must be general enough to be recognizable, but personal enough to feel worthy of our attention.

\section{Methods}

The integration of theories of usability into sound product design results in helpful sonic interfaces intended to create a consistency of experience (i.e., keeping your sonic family of beeps "on brand") and to reduce sonic interference in your day. At the same time, users create their own version of a usable soundscape by making dozens of sound design decisions through muting/silencing, setting notifications, prompting voice assistance, and customizing movement with music and podcasts. To capture the inevitable gulf between designed UI sounds and how they are taken up, I draw from published interviews with sound designers at digital media companies (Google, Twitter, Facebook, Apple) and combine this with results from a short survey on sound uses in mobile media.

\section{Works Cited}

Bull, M. (2001). The world according to sound: Investigating the world of Walkman users. New Media \& Society, 3(2), 179-197.

Bull, M. (2005). No dead air! The iPod and the culture of mobile listening. Leisure studies, 24(4), 343-355.

Collins, K. (2008). Game sound: an introduction to the history, theory, and practice of video game music and sound design. Mit Press.

Crawford, K. (2009). Following you: Disciplines of listening in social media. Continuum, 23(4), 525-535.

Lu, H., Pan, W., Lane, N. D., Choudhury, T., \& Campbell, A. T. (2009, June).

SoundSense: scalable sound sensing for people-centric applications on mobile phones. In Proceedings of the 7th international conference on Mobile systems, applications, and services (pp. 165-178). ACM.

Plotnick, R. (2013). Signal and Switch: A Cultural History of the Push-Button Interface (Doctoral dissertation, Northwestern University).

Sterne, J. (Ed.). (2012). "Sonic Imaginations." In The sound studies reader. Routledge, $1-17$.

Introcaso, James (Writer and Producer). (2017, December 11). "\#30 The Bleeps, the Sweeps, and the Creeps!" Twenty Thousand Hertz [Audio podcast]. Retrieved from https://www.20k.org/episodes/the-bleeps-the-sweeps-and-the-creeps.

Tuuri, K., Mustonen, M. S., \& Pirhonen, A. (2007). Same sound-different meanings: A novel scheme for modes of listening. Proceedings of Audio Mostly, 13-18. 
Garrett, J. J. (2001, 2010). The elements of user experience: user-centered design for the web and beyond. Pearson Education.

Norman, D. A. (2004). Emotional design: Why we love (or hate) everyday things. Basic Civitas Books.

Weis, E., \& Belton, J. (Eds.). (1985). Film sound: Theory and practice. McGill-Queen's Press-MQUP.

LoBrutto, V. (1994). Sound-on-film: Interviews with creators of film sound. Greenwood Publishing Group. 